\title{
Abnormal spindle orientation during microsporogenesis in an interspecific Brachiaria (Gramineae) hybrid
}

\author{
Andréa Beatriz Mendes-Bonato ${ }^{1}$, Maria Suely Pagliarini ${ }^{1}$ and Cacilda Borges do Valle ${ }^{2}$ \\ ${ }^{1}$ Universidade Estadual de Maringá, Departamento de Genética e Biologia Celular, Maringá, PR, Brazil. \\ ${ }^{2}$ Embrapa Gado de Corte, Campo Grande, MS, Brazil.
}

\begin{abstract}
This paper reports a case of abnormal spindle orientation during microsporogenesis in an interspecific hybrid of the tropical grass Brachiaria. In the affected plant, prophase I was normal. In metaphase I, bivalents were regularly co-oriented but distantly positioned and spread over the equatorial plate. In anaphase I, chromosomes failed to converge into focused poles due to parallel spindle fibers. As a consequence, in telophase I, an elongated nucleus or several micronuclei were observed in each pole. In the second division, the behavior was the same, leading to polyads with several micronuclei. A total of $40 \%$ of meiotic products were affected. The use of this hybrid in production systems needing good-quality seeds is discussed.
\end{abstract}

Key words: Brachiaria, interspecific hybrid, meiosis, spindle abnormality, tropical grass.

Received: November 4, 2004; Accepted: July 5, 2005.

The accurate segregation of chromosomes during mitosis and meiosis is essential to ensure normal cell division and secure the propagation of cells and hence species survival. Chromosomes segregation is mediated by a complex protein superstructure called 'the spindle' (Compton, 2000). The basis of the spindle and chromosome movements that occur during cell division has been the object of considerable speculation and hypothesis. In recent years, the forces required for spindle assembly and movements of the spindle and chromosomes have been attributed to microtubule dynamics, together with microtubule motors (Endow, 1999). Microtubules are formed by the polymeric self-organization of tubulin. This process is initiated at microtubule organizing centers (MTOCs). Discrete MTCOs, comparable to centrosomes in animals, are not known in plants (Binarová et al., 2000). In plant meiocytes, microtubules initially were found to appear around prometaphase chromosomes, indicating a chromatin-mediated spindle assembly mechanism (Chan and Cande, 1998) and in higher plants $\mathrm{Mei}$ mutations disrupting the structure and function of the division spindle in higher plants have been reported (Staiger and Cande, 1990; Staiger and Cande, 1991; Golubovskaya et al., 1992, Shamina et al., 1994). In this paper we report the spontaneous occurrence of an abnormality affecting spindle orientation in an interspecific hybrid between Brachiaria ruziziensis and Brachiaria brizantha.

Send correspondence to Maria Suely Pagliarini. Universidade Estadual de Maringá, Departamento de Genética e Biologia Celular, 87020-900 Maringá, PR, Brazil. E-mail: mspagliarini@uem.br.
We cytogenetically investigated the apomictic Brachiaria hybrid (coded as $\mathrm{Hb} 19$ ) between a $B$. brizantha $(2 \mathrm{n}=4 \mathrm{x}=36)$ as pollen donor and B. ruziziensis $(2 \mathrm{n}=4 \mathrm{x}=$ 36 ), an artificially tetraploidized sexual accession which complements some agronomic characteristics lacking in $B$. brizantha. The $\mathrm{Hb} 19$ hybrid was synthesized in 1988 by the Brazilian research organization 'Embrapa Beef Cattle' (Campo Grande, MS, Brazil) and is still undergoing agronomic evaluation, the genotype being a single plant that grown in a tuft under controlled phytosanitary conditions in the Brachiaria germplasm collection at Embrapa Beef Cattle. Inflorescences for meiotic studies were collected and fixed in a mixture of ethanol $95 \%$, chloroform, and propionic acid $(6: 3: 2 \mathrm{v} / \mathrm{v})$ for $24 \mathrm{~h}$ and refrigerated until use. Pollen mother cells (microsporocytes) were prepared by squashing and stained with $0.5 \%$ propionic carmine. More than 1800 microsporocytes were analyzed, images being photographed with Kodak Imagelink - HQ, ISO 25 black and white film.

Conventional cytological analyses revealed the occurrence of a spontaneous abnormality affecting spindle orientation in some microsporocytes of the hybrid (Table 1). In normal microsporocytes the spindle converged to form focused poles, bivalents occupied a small portion in the center of the metaphase plate and telophase nuclei presented spherical shape in both divisions (Figure 1) but in the PMCs with abnormal spindle orientation a typical phenotype similar to that of divergent spindle (dv) of maize (Clark, 1940; Staiger and Cande, 1990; Shamina et al., 2000) was recorded. Although the bivalents regularly 
Table 1 - Spindle abnormality during meiosis in Brachiaria hybrid Hb 19 microsporocytes.

\begin{tabular}{lcc}
\hline Phase & $\begin{array}{c}\text { N. of microsporocytes } \\
\text { analyzed }\end{array}$ & $\begin{array}{c}\text { N. of microsporocytes } \\
\text { affected }(\%)\end{array}$ \\
\hline Metaphase I & 314 & $71(22.61)$ \\
Anaphase I & 234 & $21(8.97)$ \\
Telophase I & 274 & $65(23.72)$ \\
Prophase II & 232 & $63(27.15)$ \\
Metaphase II & 182 & $12(6.59)$ \\
Anaphase II & 139 & $9(6.47)$ \\
TelophaseII & 192 & $59(30.73)$ \\
Tetrad & 246 & $98(39.84)$ \\
\hline
\end{tabular}

co-oriented themselves at the metaphase plate, they were distantly positioned and spread over the equatorial plate (Figure 2a), sometimes from one side of the cell wall to another. As the spindle fibers did not converge into focused poles, in anaphase the segregated chromosomes remained parallel and also failed to converge at the poles (Figure 2b). As a consequence, depending on the distance of the chromosomes at the poles, telophase I nuclei were longated shapes (Figure 2c) or were grouped into various micronuclei of different sizes (Figure $2 \mathrm{~d}$ ) in each cell. In prophase II, the nuclei remained as they were in telophase I (Figure $2 \mathrm{e}-\mathrm{g}$ ). In the second division, once more, the spindle did not form focused poles, and in metaphase II (Figure 2h) and anaphase II (Figure 2i), chromosomes were dispersed and spread over the equatorial plate. At the end of meiosis polyads with micro- and macronuclei were formed in the affected cells instead of tetrads of microspores (Figure $2 \mathrm{j}-1)$. Although the abnormal spindle orientation in this hybrid showed a typical maize $d v$ phenotype we were not able to confirm yet if the abnormality really is a mutation or an occasional phenomenon caused by environment factors. Other interspecific hybrids of the germplasm collection maintained under in the same environmental conditions have never displayed such an abnormality.

Some Brachiaria species are of considerable interest among farmers of tropical regions in Latin America due to good adaptation to the poor and acid savanna soils predominant in this area. In Brazil, most of the germplasm available was introduced from Africa through Centro Internacional de Agricultura Tropical (CIAT, Colombia) and exhibits polyploidy, which is predominantly correlated with asexual reproduction (apomixis). Although more than 50 million hectares of Brachiaria are cultivated in Brazil (Anon. 1996) only a few cultivars are used, all of which are natural apomictic tetraploids. The Brachiaria breeding program under development at Embrapa Beef Cattle aims to produce hybrids by intra- and interspecific crosses using sexual accessions as mother plants and apomictic accessions as pollen donors. To be widely utilized in production systems, besides good overall dry matter production and nutritive value, hybrids must produce a good amount of viable seeds. Thus fertile pollen grains are needed to produce normal vigorous endosperm. Some abnormalities affecting pollen fertility have been identified in accessions of different species of the Brachiaria germplasm collection at Embrapa Beef Cattle (Mendes-Bonato et al., 2001a,b, 2002; Risso-Pascotto et al., 2002, 2003; Junqueira Filho et al., 2003 ) but more so in interspecific hybrids (Mendes-Bonato
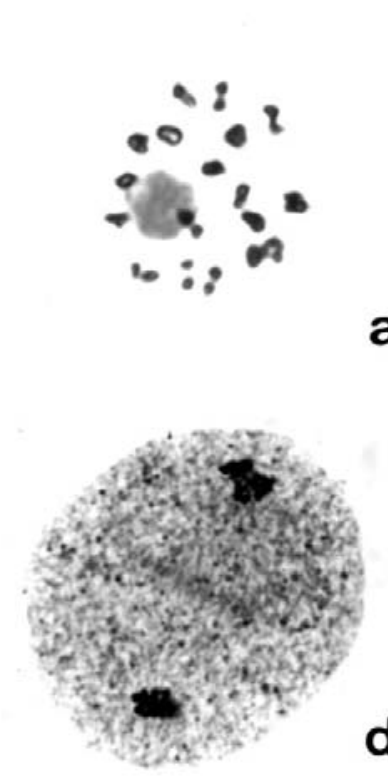

a

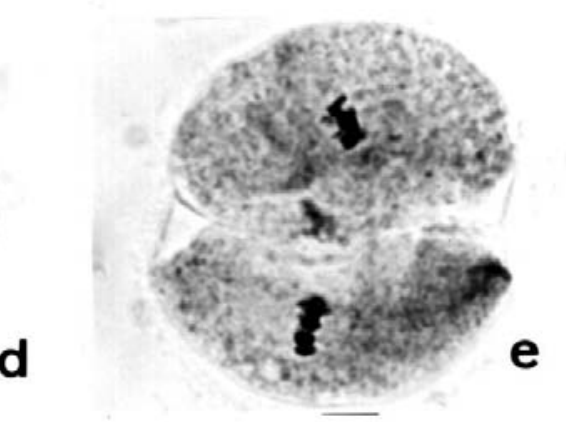

b

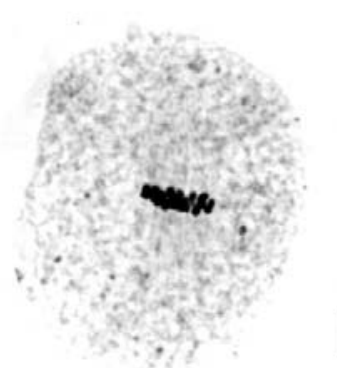

b
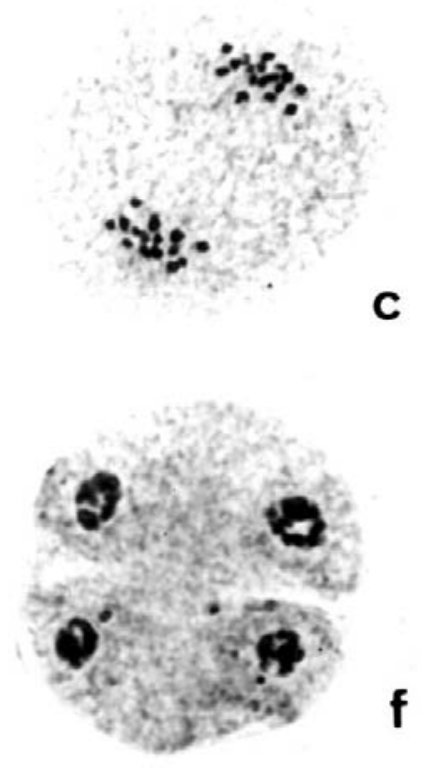

Figure 1 - Normal Brachiaria microsporocytes showing normal spindle orientation in both meiotic divisions. (a) Diakinesis $(2 \mathrm{n}=4 \mathrm{x}=36$; $18 \mathrm{II})$. (b) Metaphase I. (c) Anaphase I. (d) Telophase I. (e) Metaphase II. (f) Telophase II. (400x). 


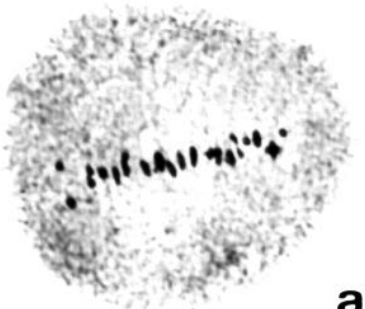

a

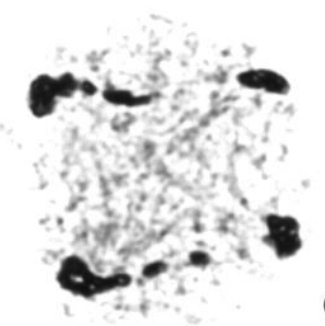

d
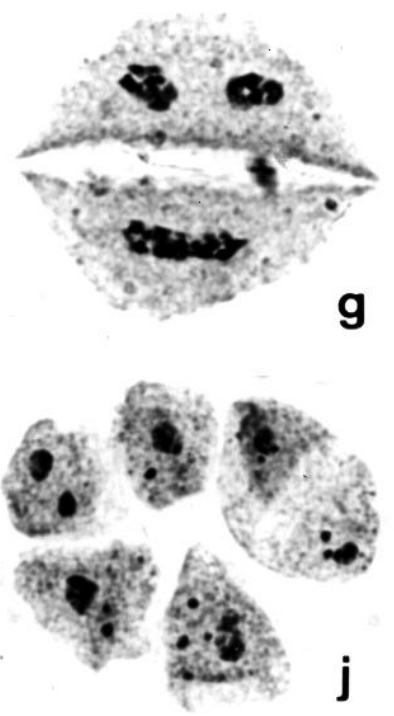

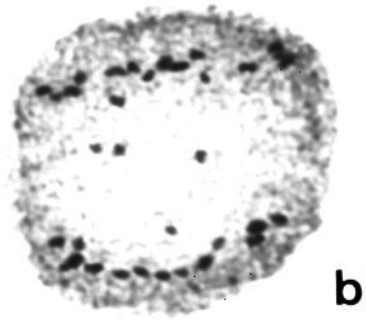

b

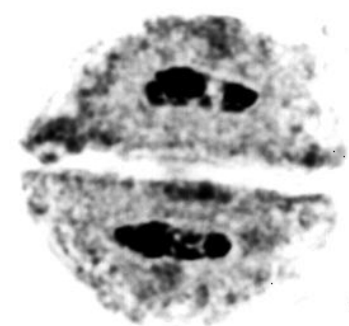

e
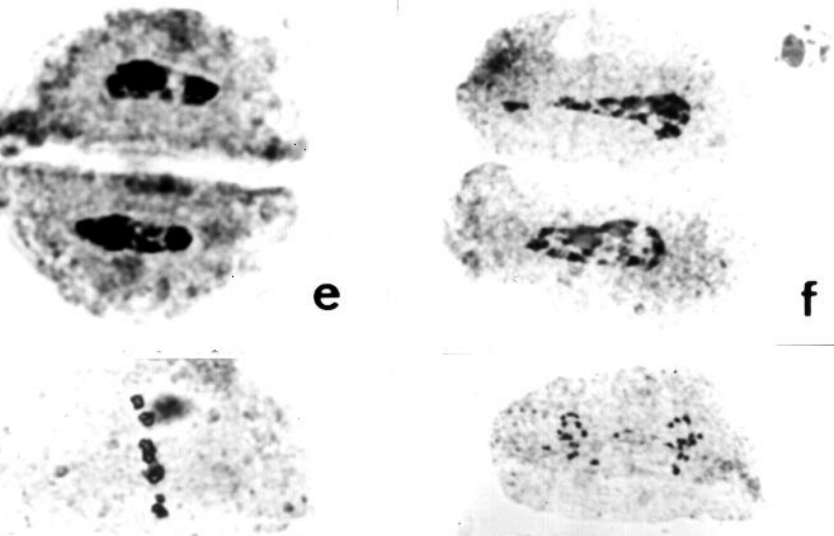

h

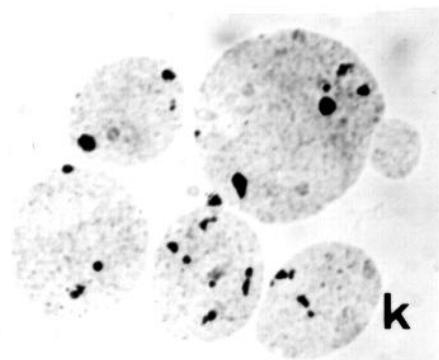

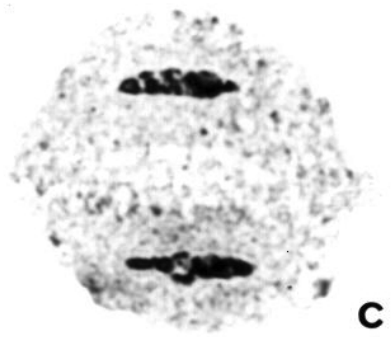

,
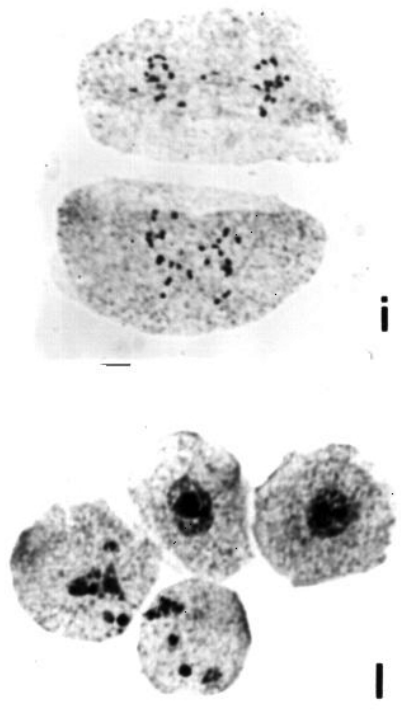

Figure 2 - Hybrid $\mathrm{Hb} 19$ Brachiaria microsporocytes with abnormal spindle orientation in both meiotic divisions. (a) Metaphase I with bivalents broadly distributed along the metaphase plate. (b) Late anaphase I with chromosomes occupying both entire poles, i.e., chromosomes did not congregate into a focused pole. (c, d) Telophases I, observe that in (c) the chromosomes were grouped forming two nuclei while in (d) the chromosomes formed several micronuclei occupying the poles. (e, f, g) Prophases II, note two elongated nuclei in (e) and (f) and one elongated nucleus and two small nuclei in ( $\mathrm{g}$ ). (h) Metaphase II with chromosomes broadly distributed along the metaphase plate. (i) Anaphase II. (j) Pentad with several micronuclei (k, 1) Abnormal meiotic products with microspores showing several micronuclei (400x).

et al., 2004; Risso-Pascotto et al., 2004 a,b) severely compromising pollen viability.

The $\mathrm{Hb} 19$ abnormality in the meiotic spindle orientation affected $40 \%$ of the tetrads, but other abnormalities detected during microsporogenesis increased the production of abnormal microspores to $45 \%$. With such a level of abnormalities, the $\mathrm{Hb} 19$ hybrid compromises the breeding program as a pollen donor but could also turn out improper as a cultivar due to its low efficiency in fertile seed production. This apomictic hybrid has proven especially productive in agronomic trials but seed production is just now being evaluated. Abnormalities detected in cell division in this study need to be correlated to seed production in order to verify if apomixis has counteracted or bypassed meiotic problems and produced enough fertile pollen to ensure proper endosperm formation and seed fill.

\section{References}

Anon (1996) Censo Agropecuário 1995-1996, Brasil. IBGE, Rio de Janeiro, pp 1-136.

Binarová P, Cenklová V, Hause B, Kubátová E, Lysák M, Dolezel J, Bögre L and Dráber P (2000) Nuclear $\Upsilon$-tubulin during acentriolar plant mitosis. Plant Cell 12:433-442. 
Chan A and Cande WZ (1998) Maize meiotic spindle assemble around chromatin and do not require paired chromosomes. J Cell Sci 111:3508-3515.

Clark FJ (1940) Cytogenetic studies of divergent meiotic spindle formation in Zea mays. Am J Bot 27:547-559.

Compton A (2000) Spindle assembly in animal cells. Annu Rev Biochem 69:95-114.

Endow SA (1999). Microtubule motors in spindle and chromosome motility. Eur J Biochem 262:12-18.

Golubovskaya IN, Avalkina NA and Sheridan WF (1992) Effects of several meiotic mutations of female meiosis in maize. Devel Genet 13:411-424.

Junqueira Filho RG, Mendes-Bonato AB, Pagliarini MS, Bione NCP, Valle CB and Penteado MIO (2003) Absence of microspore polarity, symmetric divisions and pollen cell fate in Brachiaria decumbens (Gramineae). Genome 46:83-88.

Mendes-Bonato AB, Pagliarini MS, Valle CB and Penteado MIO (2001a) Archesporial syncytes restricted to male flowers in a hexaploid accession of Brachiaria brizantha (Hochst) Stapf (Gramineae). Nucleus 44:137-140.

Mendes-Bonato AB, Pagliarini MS, Valle CB and Penteado MIO (2001b) A severe case of chromosome stickiness in pollen mother cells of Brachiaria brizantha (Hochst) Stapf (Gramineae). Cytologia 66, 287-291.

Mendes-Bonato AB, Junqueira Filho RG, Pagliarini MS, Valle CB and Penteado MIO (2002) Unusual cytological patterns of microsporogenesis in Brachiaria decumbens: Abnormalities in spindle and defective cytokinesis causing precocious cellularization. Cell Biol Int 26:641-646.
Mendes-Bonato AB, Pagliarini MS, Valle CB and Jank L (2004) Abnormal pollen mitoses (PM I and PM II) in an interspecific hybrid of Brachiaria ruziziensis and Brachiaria decumbens (Gramineae). J Genet 83:279-283.

Risso-Pascotto C, Pagliarini MS and Valle CB (2002) Abnormal nucleolar cycle in microsporogenesis of Brachiaria decumbens (Gramineae). Cytologia 67:355-360.

Risso-Pascotto C, Pagliarini MS and Valle CB (2003) A mutation in the spindle checkpoint arresting meiosis II in Brachiaria ruziziensis. Genome 46:724-728.

Risso-Pascotto C, Pagliarini MS, Valle CB and Jank L (2004a) Asynchronous meiosis in an interspecific hybrid of Brachiaria ruziziensis and B. brizantha. Plant Cell Rep 23:304-310.

Risso-Pascotto C, Pagliarini MS, Valle CB and Jank L (2004b) Asynchronous meiotic rhythm as the cause of selective chromosome elimination in an interspecific Brachiaria hybrid. Plant Cell Rep 22:945-950.

Shamina NV, Ruzankina YAS and Sosnikhina SP (1994) Spindle anomalies caused by mutation mei10 in male meiosis in rye. Tsitologia 36:189-194.

Shamina N, Dorogova N and Trunova S (2000) Radial spindle and the phenotype of the maize meiotic mutant, $d v$. Cell Biol Int 24:729-736.

Staiger CJ and Cande WZ (1990) Microtubule distribution in $d v$, a maize meiotic mutant defective in the prophase to metaphase transition. Dev Biol 138:231-242.

Staiger CJ and Cande WZ (1991) Microfilament distribution in maize mutants correlates with microtubule organization. Plant Cell 3:637-644.

Associate Editor: Marcelo Guerra 